Document downloaded from:

http://hdl.handle.net/10251/136157

This paper must be cited as:

Moliner, C.; Bosio, B.; Arato, E.; Ribes-Greus, A. (2016). Thermal and thermo-oxidative characterisation of rice straw for its use in energy valorisation processes. Fuel. 180:71-79. https://doi.org/10.1016/j.fuel.2016.04.021

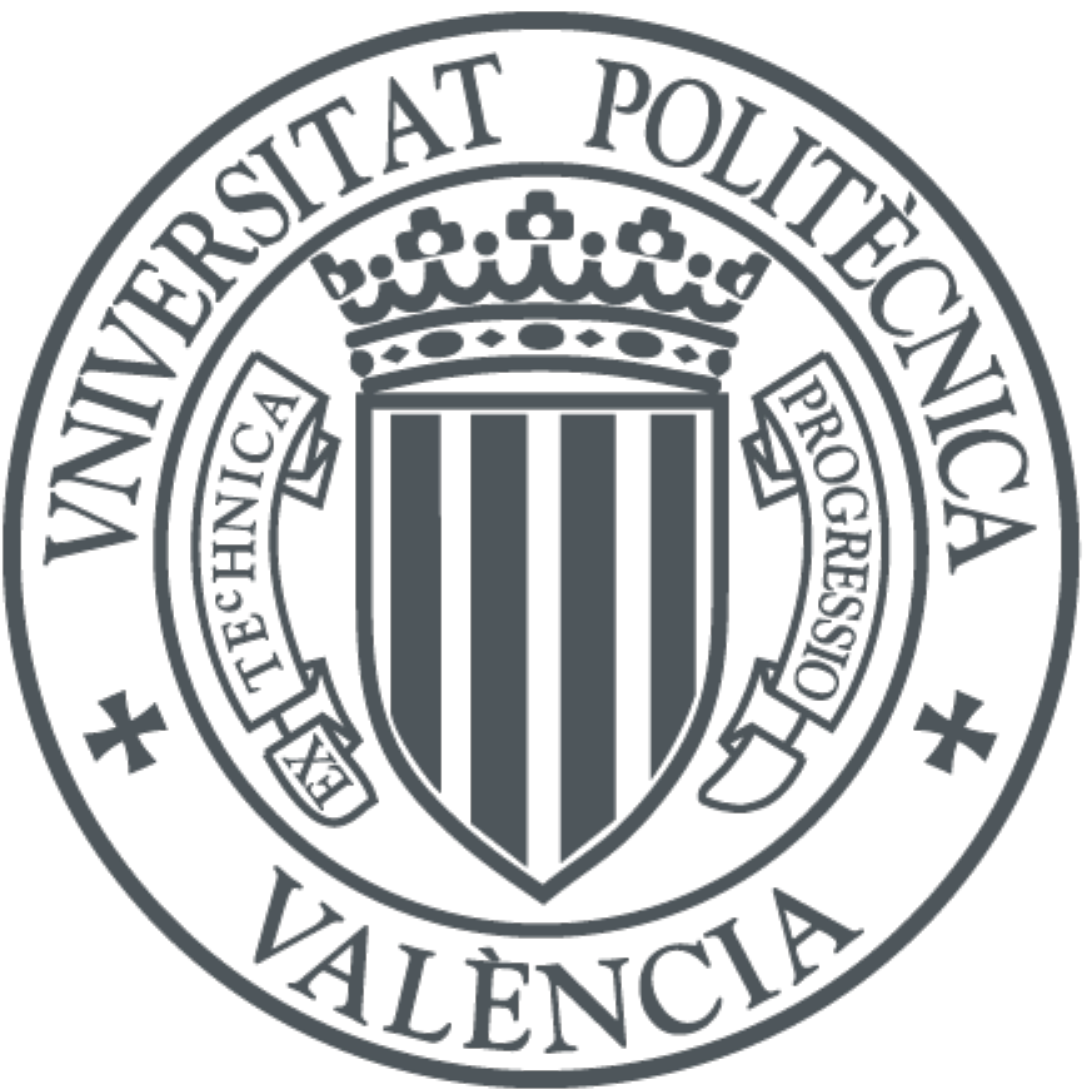

The final publication is available at

https://doi.org/10.1016/j.fuel.2016.04.021

Copyright Elsevier

Additional Information 


\title{
Thermal and thermo-oxidative characterisation of rice straw for its use in energy valorisation processes
}

\author{
C.Moliner $^{\mathrm{a} *}$, B.Bosio $^{\mathrm{a}}$, E.Arato $^{\mathrm{a}}$, A.Ribes $^{\mathrm{b}}$
}

\begin{abstract}
The processes of pyrolysis and combustion of rice straw will be carried out in a spouted bed reactor. Both thermo-chemical processes were simulated in the first stage by multirate linear non-isothermal thermogravimetric (TGA) experiments using $\mathrm{Ar}$ and $\mathrm{O}_{2}$ as carrier gas respectively. The results obtained from the TGA measurements, the kinetic methodology based on the combination of the iso-conversional methods Friedman, Flynn-Wall-Ozawa, Kissinger-Akahira-Sunose, Vyazovkin and the use of Master Plots assessed by Perez-Maqueda criterion have permitted to describe mathematically both thermo-chemical reactions. Lower operational temperatures and higher kinetic parameters (Ea, n, A) were required to carry out combustion reactions respect to those for pyrolysis. These results will be the initial parameters that will define both thermochemical processes in a spouted bed reactor.
\end{abstract}

Keywords: Rice straw, thermogravimetric analysis; thermal decomposition; thermooxidative decomposition; apparent activation energy; kinetic triplet 


\section{List of abbreviations and symbols}

$\alpha$ Degree of conversion

$\beta$ Heating rate of thermogravimetric analysis $\left({ }^{\circ} \mathrm{C} / \mathrm{min}\right)$

DTG First-derivative thermogravimetric curve

Ea Apparent activation energy $(\mathrm{J} / \mathrm{mol})$

$\mathrm{Ea}_{\text {iso }}$ Average apparent activation energy $(\mathrm{J} / \mathrm{mol})$

FWO Flynn-Wall-Ozawa

HHV High heating value (J/kg)

KAS Kissinger-Akahira-Sunose

MP Master plots

$\mathrm{MP}_{f, g}$ Differential and integral form of MP

n Order in kinetic functions

SBR Spouted bed reactor

$\mathrm{T}_{\mathrm{d}}(\beta)$ Decomposition temperature as function of the heating rate $\left({ }^{\circ} \mathrm{C}\right)$

TG Thermogravimetric curve

TGA Thermogravimetric analysis

$\mathrm{T}_{\mathrm{pi}}$ Peak temperatures of the pseudo-components of the straw

VYZ Vyazovkin

ZDT Zero-decomposition temperature $\left({ }^{\circ} \mathrm{C}\right)$ 


\section{Introduction}

Rice is one of the most consumed crops worldwide, with an annual production of 700 million tons according to the Food and Agriculture Organization of the United Nations [1] database resulting in a generation of 3.4 million tons of rice straw in Europe. Inefficient management of this waste can result in large waste dumps which can cause health problems and environmental damage. Open field burning is vastly used to eliminate these residues nowadays (30\%) while the rest is left in the fields with the consequent associated environmental problems that both procedures can generate.

Thermo-chemical conversions of rice straw have been proposed as an alternative to these management strategies taking profit of its capacity for energy production, with high heating values around $15 \mathrm{MJ} / \mathrm{Kg}$ as stated by Lim et al [2].. Among the different available techniques, Spouted Bed Reactors (SBR) has emerged as an adequate technology to carry out these processes [3]. Rice straw will constitute the main feedstock of a thermochemical process carried out in a SBR, obtained by replacing the perforated plate of a standard fluidised reactor with a simple orifice, normally in a central position. As a result, the solid circulation is enhanced and stagnant zones are avoided improving the mass and heat transfer phenomena. This behaviour provides the system with important advantages as fuel flexibility with the possibility of handling particles of different sizes and morphologies and low operating temperature conditions. The initial difficulties encountered by conventional fluidisation when applied to agricultural residues can thus be overcome.

However, as a consequence of the main properties of the feedstock like its high ash content and the low conversion efficiency, an exhaustive control of the process in terms of thermal conversions will be crucial to obtain higher efficiencies. 
Thermal studies including decomposition profiles, reaction kinetics and thermal behaviour of the raw material will be crucial to optimise the performance of the SBR.

Thermogravimetric Analysis (TGA) is a widely used technique to assess the thermal stability and decomposition kinetics of biomass. Few works have studied the thermal properties of rice straw by means of thermal analysis [4]. From the kinetic analysis, valuable parameters related to the thermo-chemical process can be obtained such as the activation energy (Ea) and the pre-exponential factor (A), both highly dependent on the temperature of reaction. Furthermore, the composition of the raw material can also be provided by thermal studies as reported in [5] as a result of the quantification of the different processes of mass loss observed during the heating process.

The main aim addressed in the present work is to characterise and compare the thermochemical conversions of rice straw by means of thermogravimetric analysis. The kinetic methodology based on the combination of the iso-conversional methods Friedman, Flynn-Wall-Ozawa, Kissinger-Akahira-Sunose, Vyazovkin and the use of Master Plots assessed by Perez-Maqueda criterion permitted to describe mathematically both thermochemical reactions. The results will define the further use of rice straw as feedstock in energy recovery processes. The thermal parameters will be used for the adequate design of pyrolysis and combustion processes in a spouted bed reactor where the thermal recovery reactions will be carried out.

\section{Materials and methods}

\subsection{Materials and sample preparation}

Rice straw was collected from the region of Valencia (Spain). The samples were washed, dried and sized. 
The composition of the rice straw was obtained according standard procedures (UNE-EN 14774-3:2009, UNE-EN 15148 and UNE-EN 14775) to obtain the distribution of products when biomass is heated under specified conditions (proximate analysis) and the composition of the biomass in base of its constituting elements (ultimate analysis). The results are reported in Table 1.

Table 1: Proximate and ultimate analysis of rice straw

\begin{tabular}{lllllllll}
\multicolumn{3}{l}{ Ultimate analysis (wt\%) } & \multicolumn{6}{c}{ Proximate analysis (wt\%) } \\
\hline $\mathrm{C}$ & $\mathrm{H}$ & $\mathrm{N}$ & $\mathrm{S}$ & $\mathrm{O}$ & Moisture & Ash $^{\mathrm{a}}$ & Volatiles $^{\mathrm{a}}$ & Fixed Carbon $^{\mathrm{a}}$ \\
\hline $\begin{array}{l}\text { 34,803 } \\
\text { a dry basis }\end{array}$ & 4,986 & 2,191 & 0,204 & 57,816 & 9,1 & 20,6 & 63,3 & 16,1
\end{tabular}

The higher heating value was obtained by application of the relation by Channiwala and Parikh [6]:

$H H V(M J / k g)=0.3491 \cdot \% C+1.1783 \cdot \% H+0.1005 \cdot \% S-0.1034 \cdot \% O-0.0151 \cdot \% N-0.0211 \cdot \% A$

Where $\mathrm{C}, \mathrm{H}, \mathrm{S}, \mathrm{O}, \mathrm{N}$ and $\mathrm{A}$ are the content (\%w/w) of carbon, hydrogen, sulphur, oxygen, nitrogen and ash in the samples. The calculated $\mathrm{HHV}$ was $11.6 \mathrm{MJ} / \mathrm{kg}$ indicating the suitability of the rice straw for thermo-chemical conversion processes.

\subsection{Thermogravimetric analyses}

Multi-rate non-isothermal thermogravimetric experiments (TGA) were carried out in a Mettler Toledo TGA/SDTA 851 (Columbus, OH). Samples weighing about 6 mg were heated in an alumina holder with capacity for $70 \mu$ l. Experiments were performed from $25^{\circ} \mathrm{C}$ to $800^{\circ} \mathrm{C}$ at different heating rates $\left(\beta=2,5,10,15,20^{\circ} \mathrm{C} / \mathrm{min}\right)$ under a constant flow of $50 \mathrm{ml} / \mathrm{min}$ of gas of analysis. 
All samples were analysed under inert $(\mathrm{Ar})$ and oxidative $\left(\mathrm{O}_{2}\right)$ atmospheres to characterise the thermal and thermo-oxidative processes respectively. Experiments were repeated three times and the average values were considered as representative values. Assessment was performed with the aid of the software Star 9.10 from Mettler Toledo.

\section{Results and discussion}

\subsection{Thermal and thermo-oxidative decomposition profiles}

The thermal performance of the rice straw was initially addressed. The thermogravimetric curves (TG) and their first derivative curves (DTG) were obtained for each sample at all heating rates $\beta$ and compared between them. Figure 1 represents the TG (inset) and DTG curves of rice straw for all $\beta$ under inert (a) and oxidative (b) conditions.
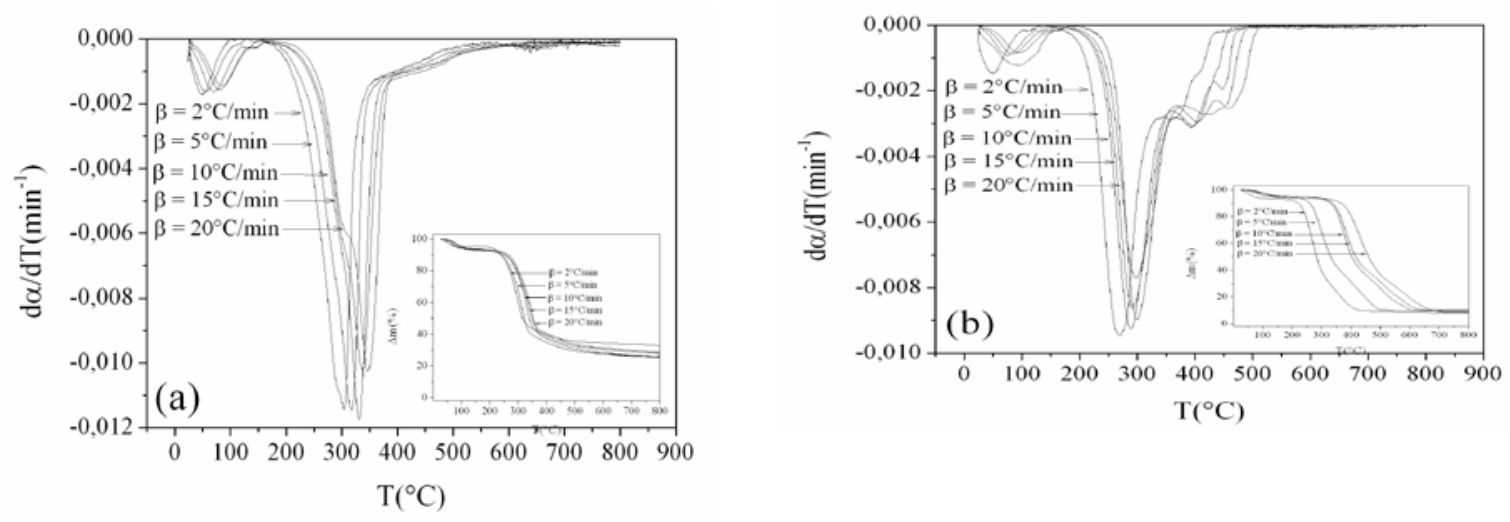

Figure 1. TG (inset) and DTG curves for rice straw at all $\beta$ at inert (a) and oxidative (b) conditions

A visual observation of the thermograms reveals three well differentiated stages, regardless the heating rate and atmosphere employed during the analysis. 


\subsubsection{Stage 1. Drying.}

The material started to decompose at $\mathrm{T} \approx 25^{\circ} \mathrm{C}$ in all cases as a result of the evaporation of moisture and absorbed water due to the hygroscopic nature of the rice straw. This peak was identified as the drying stage and it occurred below $125^{\circ} \mathrm{C}$ in all cases. The process was found to follow the same trend for all the samples.

\subsubsection{Stage 2. Devolatilisation}

Stage 2 is considered to be the step in which most of the devolatilisation reactions take place and therefore, its study will be addressed in great detail. Its complete definition in terms of temperature of degradation and kinetics of decomposition will be the basis for the correct design of the spouted bed reactor to obtain the highest yields. The majority of the initial mass was consumed during this second degradation process at the range $\mathrm{T} \approx$ $200^{\circ} \mathrm{C}-400^{\circ} \mathrm{C}$.

Two different behaviors were observed depending on the applied conditions: a single peak was obtained under oxidative conditions whereas two overlapped peaks, a shoulder together with the main peak, were observed for the case of inert atmosphere.

The presence of this shoulder indicated that more than one reaction was being involved with a higher mechanism complexity. In both cases, the molecular origin of this step is the same and it is related to the emissions of volatiles and low molecular weight compounds mainly associated to the decomposition of hemicellulose and cellulose and, in smaller amounts, lignin. 


\subsubsection{Stage 3. Combustion}

The last stage $\left(\mathrm{T}>400^{\circ} \mathrm{C}\right)$ is mainly assigned to the rapid thermo-oxidation of the remaining combustible components which are more resistant to the thermo-degradation as lignin, whose decomposition occurs in a slow velocity and a wide range of temperatures resulting in high char yields that also burn in this stage. The presence of two peaks indicates a more complex mechanism of reaction. Its higher resistance to thermal decomposition compared to hemicellulose and cellulose is due its complex structure and it is favored in the presence of oxygen. However, due to the difficulty to properly separate these two peaks and, for the purpose of this work, they will be mathematically treated as a single process.

The value of the final residue reached values over $20 \%$ for the case of samples under inert atmosphere whereas values around $5 \%$ were found at oxidative conditions. The whole decomposition scheme is in agreement with previous works on lignocellulosic materials [7].

Figure 2 shows the dependence of the thermal process with the factors of study (heating rate and atmosphere of work) with selected previous curves. 


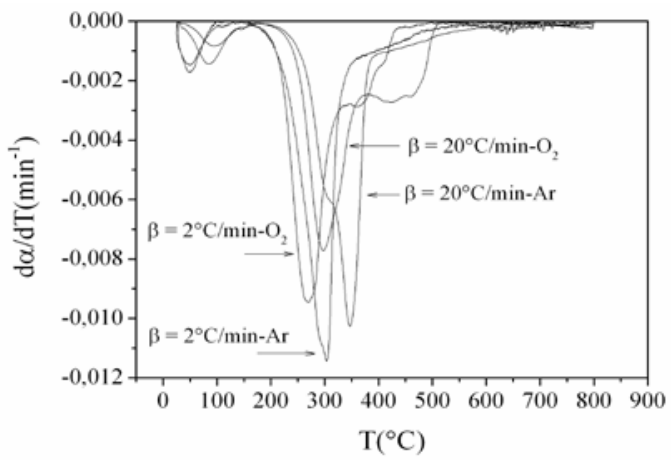

Figure 2. Influence of the heating rate and atmosphere of work on the thermal decomposition of rice straw
As expected according to previous works with different types of biomass [8], when the heating rate $\beta$ increased the thermograms shift to higher temperatures as a result of a delay in the degradation process and the sharp gradients of temperature obtained between the particle and surroundings which postpone the decomposition of biomass.

In addition, the use of an oxidative atmosphere fastened the decomposition of the material, shifting the TG curves to lower temperatures in comparison with the results obtained under inert conditions. This fact indicates a higher stability of these materials under non-reactive atmosphere due to a decrease on the reactivity in the system, as it occurred for different types of biomass in previous works [4, 9].

The presence of shoulders/double peaks in the decomposition profiles shown in Figure 1 indicates that more than one reaction is being involved at the same time. With the aim of individually characterise and quantify each decomposition process, a deconvolution procedure was applied to all samples. The deconvoluted curves and their fitting on the original data are represented in Figure 3 for inert (a) and oxidative (b) conditions. 
(a)
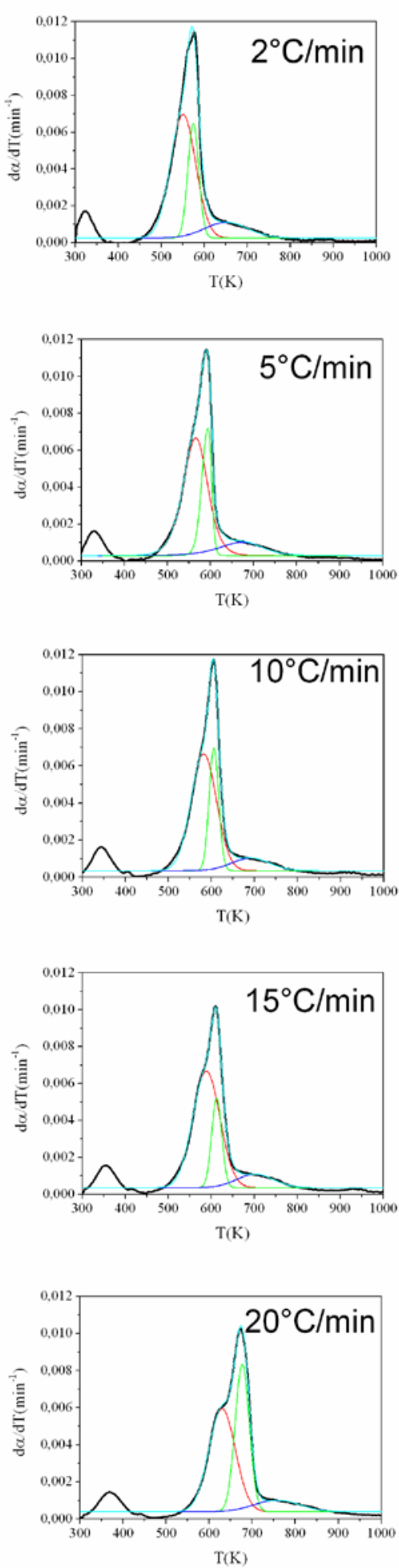

(b)
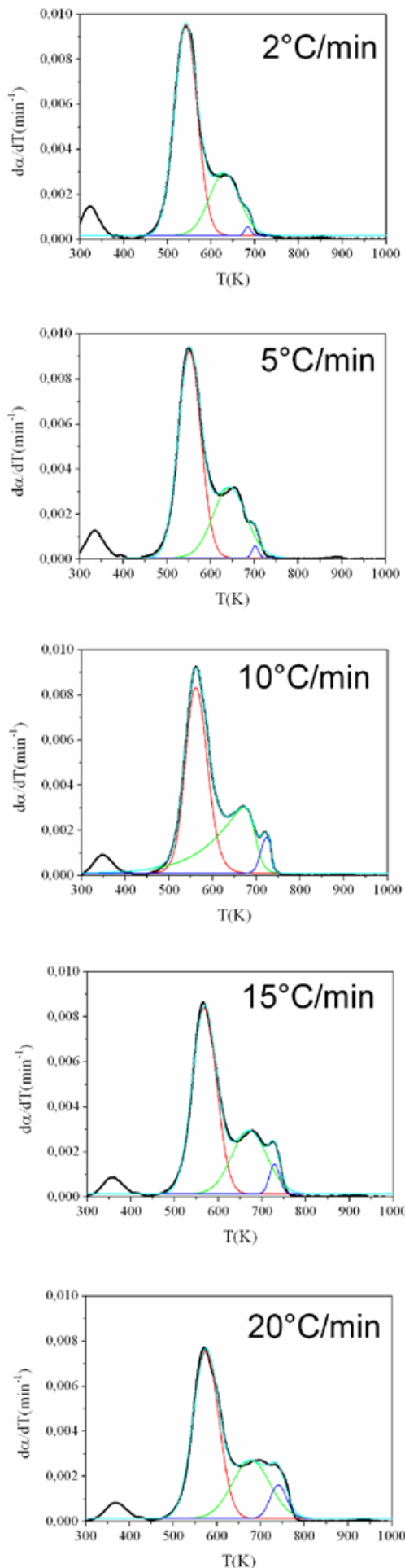

Figure 3. Deconvolution of all the pseudo-components of rice straw at all heating rates under inert (a) and oxidative (b) conditions 
All the characteristic peak temperatures $\left(T_{p i}\right.$ with $i=1 \ldots 4$ representing the different pseudo-components of the straw: moisture, hemicellulose, cellulose and lignin) for all heating rates and atmospheres are gathered in Table 2 together with the associated errors of the averaged value respect to each repetition.

Table 2. Characteristic thermogravimetric peak temperatures $(\mathrm{Tp}$, with $\mathrm{i}=1$ - 4: consecutive decomposition processes) at all heating rates under inert and oxidative conditions of work and associated error values

\begin{tabular}{|c|c|c|c|c|c|c|c|c|c|}
\hline Ar & $\beta\left({ }^{\circ} \mathrm{C} / \mathrm{min}\right)$ & $\mathrm{T}_{\mathrm{p} 1}\left({ }^{\circ} \mathrm{C}\right)$ & $e(\%)$ & $\mathrm{T}_{\mathrm{p} 2}\left({ }^{\circ} \mathrm{C}\right)$ & $\mathrm{e}(\%)$ & $\mathrm{T}_{\mathrm{p} 3}\left({ }^{\circ} \mathrm{C}\right)$ & $\mathrm{e}(\%)$ & $\mathrm{T}_{\mathrm{p} 4}\left({ }^{\circ} \mathrm{C}\right)$ & $\mathrm{e}(\%)$ \\
\hline & 2 & 50,1 & 1,1 & 289,2 & 2,6 & 303,7 & 1,0 & 430,0 & 3,7 \\
\hline & 5 & 57,3 & 0,8 & 290,8 & 2,4 & 316,9 & 1,2 & 445,0 & 4,5 \\
\hline & 10 & 71,5 & 1,4 & 291,4 & 1,8 & 330,6 & 0,9 & 462,0 & 2,4 \\
\hline & 15 & 81,6 & 0,9 & 301,4 & 2,5 & 335,6 & 4,3 & 465,0 & 3,3 \\
\hline & 20 & 86,1 & 1,6 & 313,6 & 3,3 & 346,6 & 2,1 & 470,0 & 5,1 \\
\hline $\mathrm{O}_{2}$ & $\beta\left({ }^{\circ} \mathrm{C} / \mathrm{min}\right)$ & $\mathrm{T}_{\mathrm{p} 1}\left({ }^{\circ} \mathrm{C}\right)$ & $\mathrm{e}(\%)$ & \multicolumn{3}{|c|}{$\mathrm{T}_{\mathrm{p} 2}\left({ }^{\circ} \mathrm{C}\right)-\mathrm{T}_{\mathrm{p} 3}\left({ }^{\circ} \mathrm{C}\right)$} & $\mathrm{e}(\%)$ & $\mathrm{T}_{\mathrm{p} 4}\left({ }^{\circ} \mathrm{C}\right)$ & $\mathrm{e}(\%)$ \\
\hline & 2 & 51,4 & 4,1 & \multicolumn{3}{|c|}{270,5} & 5,0 & 378,3 & 2,3 \\
\hline & 5 & 62,9 & 5,3 & \multicolumn{3}{|c|}{273,0} & 5,2 & 387,4 & 4,0 \\
\hline & 10 & 74,6 & 2,8 & \multicolumn{3}{|c|}{287,7} & 4,1 & 402,3 & 4,6 \\
\hline & 15 & 83,8 & 5,6 & \multicolumn{3}{|c|}{291,6} & 6,8 & 408,9 & 5,9 \\
\hline & 20 & 95,4 & 5,1 & \multicolumn{3}{|c|}{297,1} & 5,7 & 419,8 & 4,4 \\
\hline
\end{tabular}

The choice of the adequate temperature of work for the reactor will define the characteristics of the final product of the reaction and its correct assessment will be necessary for achieving the optimized working conditions.

Table 3 gathers the values of mass loss associated to each of the previously calculated $T_{p i}$ corresponding to the different degradation processes for all heating rates and atmospheres and the obtained errors of the averaged value respect to each repetition. 
Table 3. Mass loss $\left(\mathrm{m}_{\mathrm{i}}\right.$, with $\mathrm{i}=1-4$ : consecutive decomposition processes) due to the decomposition process of the rice straw at all heating rates under inert and oxidative conditions of work and associated error values.

\begin{tabular}{|c|c|c|c|c|c|c|c|c|c|c|c|}
\hline $\mathrm{Ar}$ & $\beta\left({ }^{\circ} \mathrm{C} / \mathrm{min}\right)$ & $\Delta \mathrm{m}_{1}(\%)$ & $\mathrm{e}(\%)$ & $\Delta \mathrm{m}_{2}(\%)$ & $\mathrm{e}(\%)$ & $\Delta \mathrm{m}_{3}(\%)$ & $\mathrm{e}(\%)$ & $\Delta \mathrm{m}_{4}(\%)$ & $\mathrm{e}(\%)$ & Residue (\%) & $\mathrm{e}(\%)$ \\
\hline & 2 & 12,1 & 9,8 & 14,0 & 8,8 & 36,0 & 9,1 & 3,0 & 6,6 & 33,7 & 6,5 \\
\hline & 5 & 8,4 & 4,5 & 24,1 & 3,1 & 34,0 & 7,4 & 6,9 & 4,7 & 25,8 & 4,2 \\
\hline & 10 & 6,9 & 5,7 & 22,6 & 5,0 & 33,1 & 8,4 & 6,9 & 10,3 & 28,0 & 5,9 \\
\hline & 15 & 7,0 & 5,3 & 17,8 & 5,1 & 36,8 & 5,6 & 8,9 & 3,5 & 28,9 & 5,5 \\
\hline & 20 & 6,8 & 7,1 & 25,9 & 7,6 & 33,6 & 5,0 & 6,7 & 9,7 & 25,4 & 8,1 \\
\hline $\mathrm{O}_{2}$ & $\beta\left({ }^{\circ} \mathrm{C} / \mathrm{min}\right)$ & $\Delta \mathrm{m}_{1}(\%)$ & $\mathrm{e}(\%)$ & \multicolumn{3}{|c|}{$\Delta \mathrm{m}_{2}(\%)+\Delta \mathrm{m}_{3}(\%)$} & $\mathrm{e}(\%)$ & $\Delta \mathrm{m}_{4}(\%)$ & $e(\%)$ & Residue (\%) & $\mathrm{e}(\%)$ \\
\hline & 2 & 9,7 & 1,4 & \multicolumn{3}{|c|}{49,3} & 5,9 & 31,7 & 9,3 & 8,0 & 7,9 \\
\hline & 5 & 7,3 & 0,8 & \multicolumn{3}{|c|}{54,0} & 9,2 & 30,9 & 11,4 & 7,8 & 8,2 \\
\hline & 10 & 6,7 & 1,1 & \multicolumn{3}{|c|}{58,6} & 5,4 & 24,9 & 6,9 & 8,8 & 7,0 \\
\hline & 15 & 7,2 & 1,0 & \multicolumn{3}{|c|}{59,4} & 8,8 & 23,8 & 7,2 & 9,5 & 7,2 \\
\hline & 20 & 7,0 & 1,3 & \multicolumn{3}{|c|}{47,0} & 8,2 & 35,8 & 6,2 & 9,5 & 9,6 \\
\hline
\end{tabular}

As stated before, the major mass loss occurs in the range of $\mathrm{T} \approx 200^{\circ} \mathrm{C}-400^{\circ} \mathrm{C}$, mainly corresponding to hemicellulose and cellulose decompositions. The two peaks corresponding to both compounds are well defined in the case of reactions of pyrolysis and their deconvolution provided the individual mass loss for decompositions each process labelled $\Delta \mathrm{m}_{2}$ for hemicellulose and $\Delta \mathrm{m}_{3}$ for cellulose. However, an only peak was obtained for an oxidative atmosphere. The deconvolution could not provide the two individual curves and therefore the calculated mass loss was taken as the total of both hemicellulose and cellulose decompositions processes $\left(\Delta \mathrm{m}_{2}+\Delta \mathrm{m}_{3}\right)$.

From the results in Table 3, in order to achieve the highest yields on volatile compounds, a temperature of work of $\mathrm{T}=600^{\circ} \mathrm{C}$ and high heating rates were initially set as the most adequate operational parameters for pyrolysis, obtaining the highest quantity of gas ( $\Delta \mathrm{m}_{2}+\Delta \mathrm{m}_{3}+\Delta \mathrm{m}_{4} \approx 70 \%$ ) together with the lowest residue (around $25 \%$ ), where $\Delta \mathrm{m}_{\mathrm{i}}=2,3,4$ is the loss mass of the hemicellulose cellulose and lignin respectively. 
Similarly, a $\mathrm{T}=550^{\circ} \mathrm{C}$ and low heating rates were defined as the most appropriate operational parameters for the case of combustion, obtaining the highest yields in produced gas $\left(\Delta \mathrm{m}_{2}+\Delta \mathrm{m}_{3}+\Delta \mathrm{m}_{4} \approx 85 \%\right)$ and the lowest values of residue (around $\left.10 \%\right)$.

In summary, the definition of the operational conditions will be determinant for the characteristics of the final product. Lower temperatures of work will be necessary to carry out combustion reactions, yielding higher percentages of volatile compounds and lower quantities of final residue respect to pyrolysis reactions.

These parameters are the initial design values of the spouted bed reactor that will carry out the thermo-chemical conversions. However, a deep insight on the process with the aid of the modelled solution validated with experimental results will be necessary to achieve the optimised solution. The values corresponding to the remaining residue are highly influenced by the atmosphere of work, with higher values for inert conditions as a result of a less reactive atmosphere. In the thermo-oxidation of rice straw, this parameter has special interest to design the spouted bed reactor as high percentages of residue could lead to slagging and fouling problems due to the high content of silica in the rice straw. An exhaustive control of the oxygen content in the carrier gas will be required as well as an accurate control of the maximum temperature of work in order to ensure a good performance of the spouted bed reactor.

\subsection{Thermal behavior of rice straw}

With the aim to evaluate the thermal behaviour of the rice straw and to predict the decomposition temperatures $\left(\mathrm{T}_{\mathrm{d}}\right)$ of all the processes undergone by the samples when submitted to thermo-chemical reactions, an accurate methodology by Badia et al $[10,11]$ was applied. 
Figure 4 shows the evolution of the previously calculated $T_{p i}$ at all heating rates under inert (a) and reactive (b) ambient and their associated error values in form of error bars. As shown in the figure, the trend was almost linear at high heating rate $\beta$, but it slightly bended when $\beta$ approached lower values.

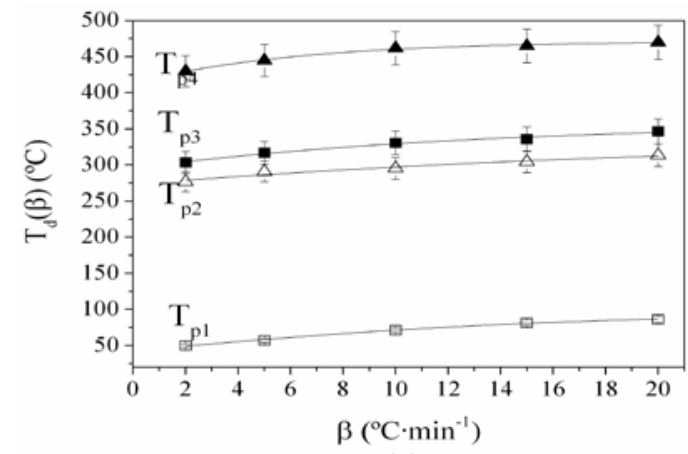

(a)

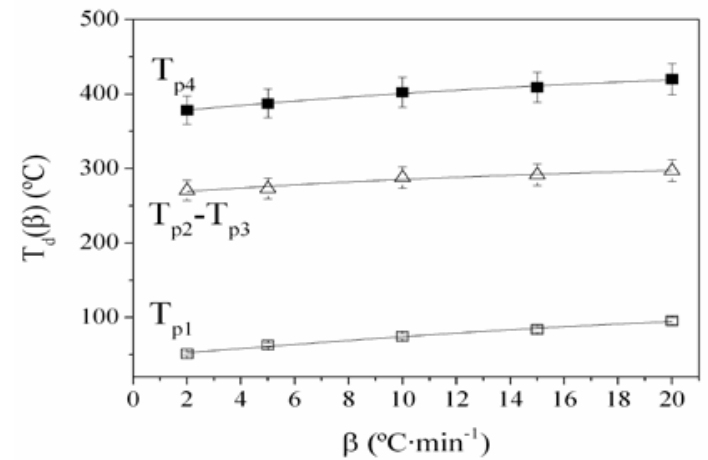

(b)

Figure 4. Application of the $\mathrm{T}_{\mathrm{d}}(\beta)$ model to assess the evolution of the peak temperatures of rice straw during the thermogravimetric analysis under inert (a) and oxidative (b) ambient and associated error bars $\left(T_{\mathrm{p} 1}\right.$ : peak of the first decomposition process, $\mathrm{T}_{\mathrm{p} 2}$ : peak of the second decomposition process, $\mathrm{T}_{\mathrm{p} 3}$ : peak of the third decomposition process, $\mathrm{T}_{\mathrm{p} 4}$ : peak of the fourth decomposition process) and associated error bars

For design purposes, it would be interesting to functionalise the thermal behaviour of rice straw under any $\beta$. In this sense, $\mathrm{T}_{\mathrm{d}}(\beta)$ was obtained as:

$$
\boldsymbol{I}_{d}(\boldsymbol{\mu}) \overline{1+\exp (-b \cdot(\beta-c))}
$$

with $\mathrm{a}, \mathrm{b}$ and $\mathrm{c}$ being the fitting parameters $[10,11]$

As it was shown before, higher heating rates led to higher characteristic temperatures. In order to avoid this influence of linear heating procedures in the evaluation of the characteristic temperatures, the so called Zero-Decomposition Temperature (ZDT) was calculated as the value obtained when the heating rate tends to zero $\left(\mathrm{T}_{\mathrm{d}}(\beta \rightarrow 0)\right)$. 
Table 4 reports the values of the fitting parameters for all temperatures at inert and oxidative atmospheres together with their standard associated error and the resulting ZDT values. The high values of $R^{2}$ in all fitting parameters indicate the suitability of $T_{d}(\beta)$ to represent the thermal behaviour of the rice straw.

Table 4. Results of fitting to Eq. 1 along with ZDT for all decomposition processes as a result of the extrapolation of Eq. 1 to $\beta \rightarrow 0$ and associated error values.

\begin{tabular}{lllllllll} 
Ar & a & e (\%) & b & e (\%) & c & e (\%) & $\mathrm{R}^{2}$ & ZDT $\left({ }^{\circ} \mathrm{C}\right)$ \\
\hline $\mathrm{Tp}_{1}$ & 94,1 & 3,6 & 0,13 & 0,02 & 1,2 & 0,5 & 0,9943 & 43,3 \\
$\mathrm{Tp}_{2}$ & 334,4 & 39,7 & 0,06 & 0,06 & $-25,8$ & 16,2 & 0,9271 & 273,4 \\
$\mathrm{Tp}_{3}$ & 355,5 & 11,6 & 0,09 & 0,04 & $-17,0$ & 6,0 & 0,9695 & 295,8 \\
$\mathrm{Tp} 4$ & 471,3 & 2,4 & 0,18 & 0,03 & $-11,3$ & 2,2 & 0,9863 & 414,3 \\
& & & & & & & & \\
$\mathbf{O}_{2}$ & a & e (\%) & b & e (\%) & c & e (\%) & $\mathrm{R}^{2}$ & ZDT $\left({ }^{\circ} \mathrm{C}\right)$ \\
\hline $\mathrm{Tp}_{1}$ & 113,4 & 14,8 & 3,42 & 2,63 & 0,10 & 0,03 & 0,9838 & 45,4 \\
$\mathrm{Tp}_{2}+\mathrm{Tp}_{3}$ & 310,4 & 0,9 & $-25,16$ & 0,00 & 0,07 & 0,00 & 0,9367 & 264,0 \\
$\mathrm{Tp}_{4}$ & 444,6 & 19,8 & 0,06 & 0,02 & $-27,86$ & 7,86 & 0,9862 & 371,6
\end{tabular}

The dependence of the thermal behaviour of the straw with the atmosphere of work is also evidenced from the evolution of the previously calculated ZDT for all the pseudocomponents of the straw (moisture-ZDT $\mathrm{p}_{\mathrm{p}}$, hemicellulose-ZDT $\mathrm{p}_{\mathrm{p}}$, cellulose-ZDT $\mathrm{p}$, lignin-ZDT $\mathrm{p}_{4}$ ), which followed the same trend as described in Section 3.1.

The values corresponding to the drying process $\left(\mathrm{ZDT}_{\mathrm{p} 1}\right)$ were very similar under both atmospheres of work, confirming the independence of the process with the used carrier gas.

The rest of the calculated ZDT $\left(\mathrm{ZDT}_{\mathrm{p} 2}, \mathrm{ZDT}_{\mathrm{p} 3}, \mathrm{ZDT}_{\mathrm{p} 4}\right)$ presented lower values when $\mathrm{O}_{2}$ was used as the reaction gas respect to those in inert ambient, confirming therefore the higher reactivity of the system when an oxidative atmosphere is applied. In terms of design of the reactor, $\mathrm{ZDT}_{\mathrm{p} 2}$ will provide the minimum temperature of work required inside the reactor to start the devolatilisation stage. 
For the case of rice straw, a minimum of $\mathrm{T}=273^{\circ} \mathrm{C}$ (inert conditions) and $\mathrm{T}=264^{\circ} \mathrm{C}$ (oxidative conditions) will be necessary to start yielding volatile compounds. These values represent the minimum operational temperature needed to start the thermochemical processes and therefore, the minimum initial energy requirements of the system.

\subsection{Decomposition kinetics}

\subsubsection{Apparent activation energies}

The kinetics of decomposition is essential parameters in the correct design of a device for thermal conversion processes. They will define the apparent activation energy (Ea) to be applied to the system to start the thermal process and will also provide information on the reaction times to complete the thermo-chemical conversions.

The isoconversional methods Friedman [12], Flynn-Wall-Ozawa (FWO) [13], Ozawa [14], Kissinger-Akahira-Sunose (KAS) [15] and Vyazovkin (VYZ) [16] were applied to evaluate the dependence of the apparent activation energy (Ea) with the conversion degree $\alpha$ defined as $\alpha=\left(m_{0}-m_{i}\right) /\left(m_{0}-m_{\infty}\right)$, where $m$ is the mass with the subscripts 0 , i and $\infty$ standing for initial, instant and final respectively.

The temperature range for all the kinetic studies was taken from $\mathrm{T} \sim 150^{\circ} \mathrm{C}$ as, at temperatures below this value, only moisture and absorbed water was removed and its kinetics did not exhibit differences with the change of heating rates.

Figure 5 shows the application of the mentioned methods along the conversion degree of each of the previously deconvoluted curves in Stage 2 (Figure 3) under inert (a) and oxidative conditions (b). 

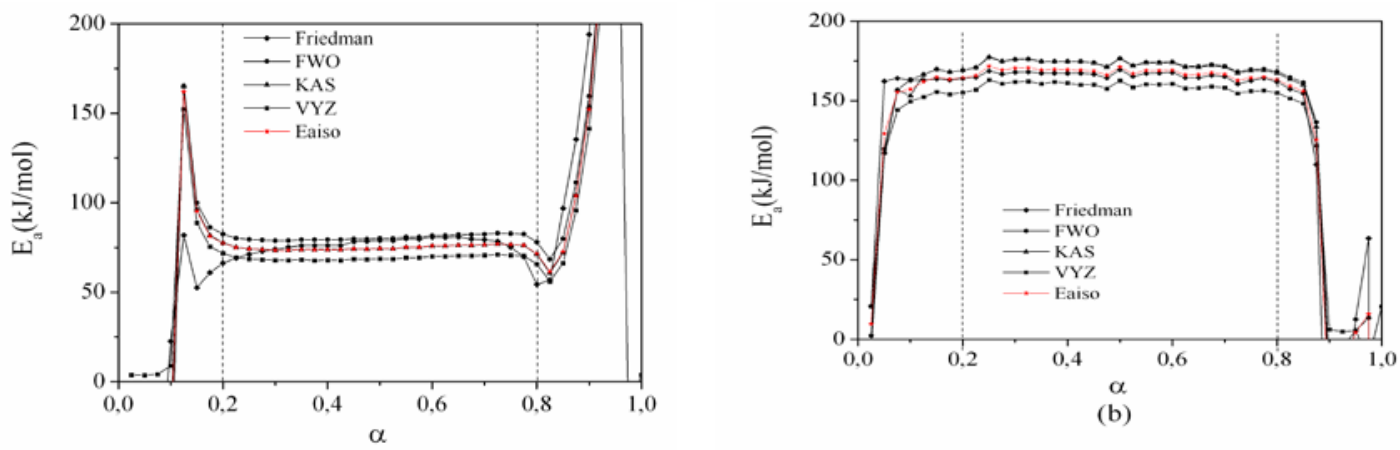

(a)

Figure 5. Evolution of Eafriedman, Eafwo, EakAs, Eavyz, Ea iso for the main decomposition process of rice straw (range $\alpha=0.2-0.8$ ) at inert (a) and oxidative (b) conditions.

All the kinetic analysis were carried out in the range $\alpha=0.2-0.8$, where the main process takes place. The average values were obtained $\left(\mathrm{Ea}_{\mathrm{iso}}\right)$ from the iso-conversional methods. The regression coefficient at the range of study for the main degradation process of the straw at inert conditions was above $90 \%$ whereas the values obtained for experiments under $\mathrm{O}_{2}$ were not below 95\%.

All the calculated values of apparent activation energy and associated errors are presented in Table 5.

As stated before, the two main peaks corresponding to the decompositions of hemicellulose (Process 1) and cellulose (Process 2) were individually calculated for inert conditions whereas a single peak represented both processes during combustion reactions.

Table 5. Values of activation energy and associated errors for the main decomposition processes of rice straw obtained by the different iso-conversional methods (Friedman, FWO, KAS, VYZ) under inert and oxidative conditions.

\begin{tabular}{ll|llllllll} 
& & $\begin{array}{l}\text { Ea Friedman } \\
(\mathrm{kJ} / \mathrm{mol})\end{array}$ & $\begin{array}{l}\text { e } \\
(\%)\end{array}$ & $\begin{array}{l}\text { Ea FWO } \\
(\mathrm{kJ} / \mathrm{mol})\end{array}$ & $\begin{array}{l}\text { e } \\
(\%)\end{array}$ & $\begin{array}{l}\text { Ea KAS } \\
(\mathrm{kJ} / \mathrm{mol})\end{array}$ & $\begin{array}{l}\text { e } \\
(\%)\end{array}$ & $\begin{array}{l}\text { Ea VYZ } \\
(\mathrm{kJ} / \mathrm{mol})\end{array}$ & $\begin{array}{l}\text { e } \\
(\%)\end{array}$ \\
\hline \multirow{2}{*}{$\mathrm{Ar}$} & Process 1 & 75,4 & 18,0 & 80,7 & 5,4 & 75,0 & 5,0 & 69,1 & 4,8 \\
& Process 2 & 66,8 & 18,5 & 61,2 & 6,2 & 53,7 & 7,3 & 50,7 & 6,0 \\
\hline $\mathrm{O}_{2}$ & Process 1+2 & 165,6 & 5,1 & 172,7 & 2,6 & 172,4 & 2,9 & 159,1 & 2,8
\end{tabular}


A higher value of apparent activation energy $\left(E a_{i s o}\right)$ was obtained for oxidative conditions. This fact has been previously reported [17] and it is attributed to the increase of oxidant reactions as a result of an increase of $\mathrm{O}_{2}$ in the carrier gas. However, this assumption should be fully subscribed by evaluating the quantity of $\mathrm{CO}_{2}$ emitted during the thermochemical processes as, due to the increase on oxidant reactions, the concentration of $\mathrm{CO}_{2}$ should also increase.

As reported in Table 5, the apparent activation energy values obtained by Friedman method presented the highest associated error. This might be caused by the differential nature of the method that leads to noisy data after the required numerical differentiation. On the contrary, VYZ method provided the least error values thanks to the application of the Senum-Yang approximation ( $5^{\text {th }}$ order) which yields most accurate results.

These values are also in agreement with previous works dealing with apparent activation energy for different agricultural residues $[18,19]$ where the obtained results fell within the range $140-180 \mathrm{~kJ} / \mathrm{mole}$ in all cases.

From a technological point of view, the apparent activation energy provides the barrier of energy that the system needs to surpass in order to start the thermo-chemical reaction and it defines a value related to the energy requirements of the spouted bed reactor. Finally, for the complete design of the reactor, the complete kinetic expression will be obtained. 


\subsubsection{Evaluation of the pre-exponential factor and the order of reaction. Completing the kinetic triplet}

The kinetic model was evaluated and defined from the kinetic analysis of the rice straw and the Master Plot reduced curves (MP) [20]. MP are defined as the theoretical reference curves dependent on the kinetic model and, generally, independent of the kinetic parameters of the process. The comparison between the experimental values and these theoretical curves permits the calculation of the appropriate kinetic model according to the better fitting of the experimental data on the master plots.

The three main types of MP are those based on the differential form $\left(\mathrm{MP}_{\mathrm{f}}\right)$ of the general kinetic equation as expressed in (3), the integral form ( $\mathrm{MPg}$ ) as in (4) or the combination of both:

$$
\begin{aligned}
& M P_{f}(\alpha)=\frac{w \omega}{d t} \equiv \beta \cdot \frac{w \omega}{d T}=A \cdot f(\alpha) \cdot k(T)=A \cdot f(\alpha) \cdot e^{R \cdot T} \\
& M I P_{g}(\alpha)=\int_{0} \frac{}{f(\alpha)}=\frac{1}{\beta \cdot R} \cdot \int_{0} \frac{}{x^{2}}=\frac{}{R \cdot T} \cdot p(X), x=\frac{}{R \cdot T}
\end{aligned}
$$

The theoretical curves coincide at $\alpha=0.5$ and so, this point is taken as a reference and all the curves are reduced to it for a better visualisation. The theoretical master plots of the different kinetic models can be clearly distinguished for $\alpha<0.5$ and $\alpha>0.5$ for the differential and integral curves, respectively, and therefore a straightforward identification can be done. 
Figure 5 shows the theoretical MPg curves and the experimental data corresponding to the main decomposition process at $20^{\circ} \mathrm{C} / \mathrm{min}$ occurring for rice straw under inert (a) and oxidative (b) conditions. The represented kinetic models are: $\mathrm{D}_{\mathrm{n}}=$ diffusion controlled (blue lines), $A_{n}=$ nucleation and growth (red lines), $F_{n}=n$-order reactions (orange lines) and $\mathrm{R}_{\mathrm{n}}=$ reactions controlled (green lines).
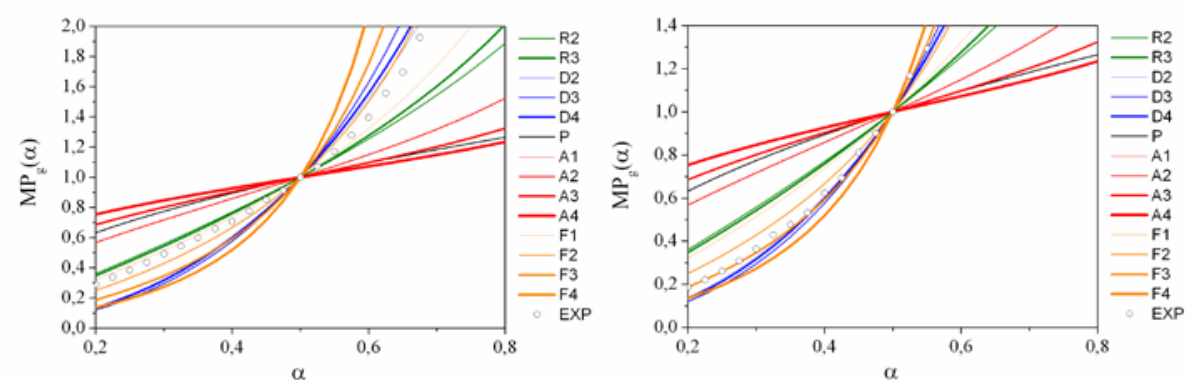

(a)

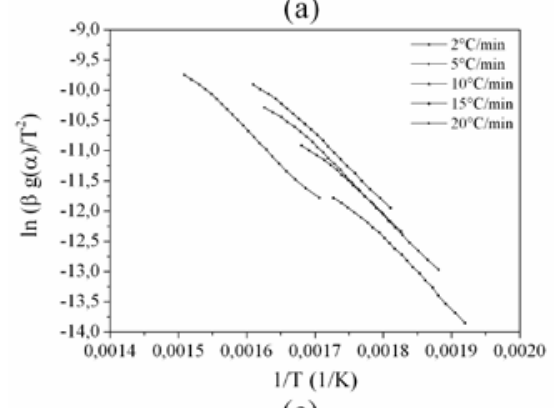

(c)

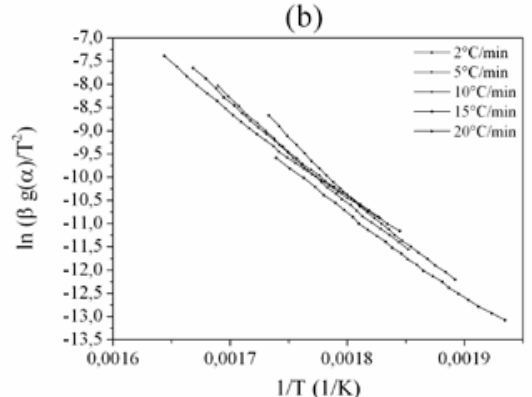

(d)

Figure 5. Master plots based on the integral $\left(\operatorname{MPg}_{\mathrm{g}}(\alpha)\right)$ form of the general law compared to the experimental data obtained by the thermal process applied (circles) for rice straw under inert (a) and oxidative (b) conditions - Application of the Perez-Maqueda criterion for the thermal decomposition or rice straw under inert (c) and oxidative (d) conditions.

According to Figure 5, the model describing the thermal degradation following a reaction order mechanism $\left(\mathrm{F}_{\mathrm{m}}\right)$. According to this model, the reaction rate is proportional to the fraction remaining of reactant(s) raised to a particular power (reaction order) [21].

The exact order of reaction was analytically obtained by accomplishing Perez-Maqueda criterion [22]; that is, the independence of the kinetic parameters Ea and A with the heating rate $\beta$. This criterion is usually employed with Ea and A invariable with the aid of the Coats-Redfern equation [23] written in the form: 


$$
\left\lfloor\mathrm{III} \frac{T^{2}}{\rfloor_{y}}=\mathrm{III} \frac{}{E a_{\beta}}+\frac{}{R} \cdot\lfloor\bar{T}\rfloor_{x}\right.
$$

with $g(\alpha)$ being the integral form of the model previously calculated.

A single straight line with slope $\left(E a_{\beta} / R\right)$ and an intercept $\ln \left(A_{\beta} \cdot R / E a_{\beta}\right)$ is obtained when the left hand side of Eq. 4 is plotted against 1/T only if the appropriate $g(\alpha)$ is chosen.

By setting the values of Eaiso as the average value of those previously calculated (Table 5) and after applying a regression method (with the aid of the tool SOLVER), the values of $\mathrm{n}$ and $\ln$ A were obtained.

Figure 5 (c) and (d) shows the representation of Eq. 5 after introducing the calculated parameters. The straight lines in the interval of study confirm the goodness of $F_{m}$ (with $m$ the analytically calculated order of reaction) as the kinetic model describing the main process of degradation for rice straw.

As a summary, the kinetic triplet associated to the main thermal decomposition process of rice straw for thermal and thermo-oxidative reactions is reported in Table 6 .

Table 6. Kinetic triplet for the main decomposition processes of rice straw for thermal and thermooxidative reactions

\begin{tabular}{l|llllll} 
& $\begin{array}{l}\text { Eaiso } \\
(\mathrm{kJ} / \mathrm{mol})\end{array}$ & $\begin{array}{l}\mathrm{e} \\
(\%)\end{array}$ & $\begin{array}{l}\mathrm{n} \\
(\text { from MP) }\end{array}$ & $\begin{array}{l}\mathrm{n} \\
\text { (analytical) }\end{array}$ & $\begin{array}{l}\mathrm{A} \\
\left(\mathrm{min}^{-1}\right)\end{array}$ & $\begin{array}{l}\mathrm{e} \\
(\%)\end{array}$ \\
\hline \multirow{2}{*}{$\mathrm{Ar}$} & 75,0 & 3,8 & $1-2$ & 1,35 & $1.1 \cdot 10^{7}$ & 0,87 \\
& 58,5 & 7,1 & 1 & 0,89 & $1.5 \cdot 10^{7}$ & 0,98 \\
\hline $\mathrm{O}_{2}$ & 167,4 & 6,7 & $2-3$ & 2,95 & $2.6 \cdot 10^{14}$ & 7,4
\end{tabular}

Finally, the following expressions were proposed to define the decomposition of the devolatilisation stage for the rice straw both for inert (Eq. 6 and 7) and oxidative conditions (Eq. 8): 


$$
\begin{aligned}
& \frac{{ }^{\text {rYKL }}}{d t}=1.1 \cdot 10^{\prime} \cdot(1-\alpha)^{1.0 د} \cdot e^{-/ 0.0 / \kappa 1}
\end{aligned}
$$

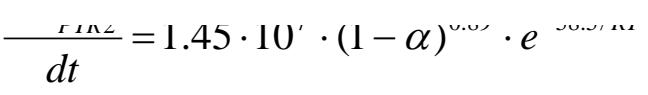

$$
\begin{aligned}
& \frac{\cdots v x}{d t}=2.6 \cdot 10^{14} \cdot(1-\alpha)^{<. J 3} \cdot e^{-10 / .4 / \pi 1}
\end{aligned}
$$

In summary, lower activation energies were required to carry out reactions of pyrolysis due to the absence of complex oxidant reactions. For the same reason, a lower order of reaction was found during pyrolysis together with lower values of the pre-exponential factor as a result of a lower reactivity of the system.

These data, together with the peak temperatures calculated in Section 3.2 and the specific fluid dynamic parameters of the spouted bed reactor, will be introduced in a commercial process simulation tool in order to simulate the described processes carried out in a spouted bed reactor and evaluate the optimised operational conditions.

\section{Conclusions}

An accurate methodology evaluated and compared the initial design parameters of a spouted bed reactor to carry out energy valorisation processes using rice straw as feedstock. 
Lower temperatures of work were necessary to carry out combustion reactions, yielding higher percentages of volatiles and lower values of residue respect to pyrolysis reactions. A correct assessment of this parameter will be essential to avoid melting and slagging problems in the reactor and its associated operational problems. A suitable kinetic triplet (Ea, A, n) and mechanism of reaction was found for the main devolatilisation process for thermal and thermo-oxidative conditions. Lower activation energies, order of reaction and pre-exponential factor values were required to carry out reactions of pyrolysis due to

the absence of complex oxidant reactions.

These parameters, together with the specific fluid dynamics of the system, will be applied as input variables in a theoretical model to describe thermal recovery processes in a spouted bed reactor using rice straw as feedstock. Efforts will be focused then on the optimization of the working conditions with the aid of the developed model to obtain the highest efficiencies ensuring a good performance of the reactor. 


\section{References}

[1] FAOSTAT (Food and Agriculture Organization of the United Nations), 2013, Production crops <faostat3.fao.org $>$ accessed 12.11.2014.

[2] Lim J.S., Manan Z.A., Rafidah S., Alwi W., Hashim H., A review on utilisation of biomass from rice industry as a source of renewable energy, Renewable and Sustainable Energy Reviews 2012, 16, 3084-3094.

[3] Epstein N., Grace J.R., Spouted and Spout-fluid beds. Fundamentals and applications. Ed. Cambridge University Press 2011.

[4] White J.E., Catallo W.J., Legendre B.L., Biomass pyrolysis kinetics: A comparative critical review with relevant agricultural residue case studies, Journal of Analytical and Applied Pyrolysis 2011, 91, Issue 1, 1-33.

[5] Carrier M., Loppinet-Serani A., Denux D., Lasnier J.M., Ham-Pichavant F., Cansell F., Monier C.A., Thermogravimetric analysis as a new method to determine the lignocellulosic composition of biomass. Biomass and Bioenergy 2011, 35, 298-307.

[6] Channiwala, S.A., Parikh P.P., A unified correlation for estimating the HHV of solid, liquid and gaseous fuels. Fuel, 2002, 81 (8) 1051-1063.

[7] Yang H., Yan R., Chen H., Ho Lee D., Zheng C., Characteristics of hemicellulose, cellulose and lignin pyrolysis, Fuel 2007, 86, 1781-1788.

[8] D.K. Shen, S. Gu, K.H. Luo, A.V. Bridgewater, M.X. Fang, Kinetic study on thermal decomposition of woods in oxidative environment, Fuel 2009, 88, 1024-1030.

[9] Amutio M., Lopez G., Aguado R., Artetxe M., Bilbao J., Olazar M., Kinetic study of lignocellulosic biomass oxidative pyrolysis, Fuel 2012, 95, 305-311.

[10] Badia JD, Santonja-Blasco L., Martinez-Felipe A., Ribes-Greus A., A methodology to assess the energetic valorization of bio-based polymers from the packaging industry: pyrolysis of reprocessed polylactide, Bioresource Technology 2012, 111, 468-475.

[11] Badia J.D,.Martinez-Felipe A., Santonja-Blasco L., Ribes-Greus A., Thermal and thermo-oxidative stability of reprocessed poly(ethylene terphthalate), Journal of Analytical and Applied Pyrolysis, 2013, 99, 191-202. 
[12] Friedman H., Kinetics of thermal degradation of char-forming plastics from thermogravimetry. Application to a phenol plastic., J. Polym. Sci. 1964, 6, 183-195.

[13] Flynn J.H., Wall L.A., A quick, direct method for the determination of activation energy from thermogravimetric data. Journal of Polymer Science 1966, 4, 323-342.

[14] Ozawa T., Kinetic analysis of derivative curves in thermal analysis. Journal of Thermal Analysis 1970, 2, 301-324.

[15] Akahira T., Sunose Trans.Joint Convention of Four Electrical Institutes, Paper N.246, Research Report/Chiba Institute of Technology. Scientific Technology, 1971, 16, 22-31.

[16] Vyazovkin S., Advanced isoconversional method, Journal of thermal analysis, 1997, 49, 1493-1499.

[17] Zhaosheng Y., Xiaoqian M., Ao L., Kinetic studies on catalytic combustion of rice and wheat straw under air- and oxygen-enriched atmospheres, by using thermogravimetric analysis. Biomass and Bioenergy, 2008, 32, Issue 11, 1046-1055.

[18] Yao F., Wu Q., Lei Y., Guo W., Xu Y., Thermal decomposition kinetics of natural fibers: Activation energy with dynamic thermogravimetric analysis, Polymer Degradation and Sustainability 2008, 93, 90-98.

[19] Mishra G., Bhaskar T., Non isothermal model free kinetics for pyrolysis of rice straw, Bioresource Technology 2014, 169, 614-621.

[20] Gotor F.J..Criado J.M, Malek J., Koga N., Kinetic analysis of solid-state reactions: the universatility of master plots for analysing isothermal and non-isothermal experiments. Journal of Physical Chemistry A 2000, 104, 10777-10782.

[21] Khawam A., Flanagan D.R., Solid-state kinetic models: basics and mathematical fundamentals, The Journal of Physical Chemistry B, 2006, 110 (35), 17315-17328.

[22] Perez-Maqueda L.A., Criado J.M., Gotor F.J., Malek J., Advantages of combined kinetic analysis of experimental data obtained under any heating rate profile, Journal of Physical Chemistry A 2002, 106, 2862-2868.

[23] Coats A.W., Redfern J.P., Kinetic parameters from thermogravimetric data. Nature 1964, 201, 68-69 